\title{
Skeleton and musculature of the male abdomen in Tanyderidae (Diptera, Nematocera) of the Southern Hemisphere
}

\author{
Olga G. Ovtshinnikova', Tatiana V. Galinskaya ${ }^{2,3}$, Elena D. Lukashevich ${ }^{4}$ \\ I Zoological Institute, Russian Academy of Sciences, Universitetskaya nab., 1, St. Petersburg 199034, Russia \\ 2 Department of Entomology, Faculty of Biology, Lomonosov Moscow State University, Leninskie gory 1-12, \\ Moscow 119234, Russia 3 Scientific-Methodological Department of Entomology, All-Russian Plant Quaranti- \\ ne Center, Pogranichnaya 32, Bykovo, Moscow region 140150, Russia 4 Borissiak Paleontological Institute of \\ Russian Academy of Sciences, Profsoyuznaya st., 123, Moscow 117647, Russia \\ Corresponding author: Tatiana V. Galinskaya (nuha1313@gmail.com)
}

Academiceditor:VladimirBlagoderov| Received11 August2018|Accepted2November2018|Published 19December2018

http://zoobank.org/D00683C7-C5D0-4CF6-A361-DEB457EA2650

Citation: Ovtshinnikova OG, Galinskaya TV, Lukashevich ED (2018) Skeleton and musculature of the male abdomen in Tanyderidae (Diptera, Nematocera) of the Southern Hemisphere. ZooKeys 809: 55-77. https://doi.org/10.3897/ zookeys.809.29032

\begin{abstract}
The structure of the male terminalia and their musculature of species of tanyderid genera Araucoderus Alexander, 1929 from Chile and Nothoderus Alexander, 1927 from Tasmania are examined and compared with each other and with published data on the likely relatives. The overall pattern of male terminalia of both genera is similar to those of most Southern Hemisphere genera, with simple curved gonostyli, lobelike setose parameres, and setose cerci inconspicuous under the epandrium. Both genera have terminalia similarly rotated by $180^{\circ}$ (and $90^{\circ}$ as an intermediate stage); rotation may be either clockwise or counterclockwise. However, the similar patterns are realized differently: segment VIII is the decreased and asymmetrical due to completely membranose tergite VIII in Nothoderus (the first record of such modification in Tanyderidae), but narrow and symmetrical in Araucoderus. Accordingly, pregenital muscles are very different between the genera. Based on localization of muscle attachment sites, the hypandrial origin of the stripe between gonocoxites is shown in both genera, and entire membranization of tergite VIII and partial membranization of hypoproct is shown in Nothoderus. Tanyderidae are characterized by highly specialized sclerites and muscles of male terminalia and provide no evidence of relationship with previously studied members of Psychodidae, Blephariceridae and Ptychopteridae.
\end{abstract}

Copyright Olga G. Ovtshinnikova et al. This is an open access article distributed under the terms of the Creative Commons Attribution License (CC BY 4.0), which permits unrestricted use, distribution, and reproduction in any medium, provided the original author and source are credited. 


\section{Keywords}

crane flies, rotation, terminalia, genitalia, morphology, Araucoderus, Nothoderus

\section{Introduction}

Tanyderidae, or primitive crane flies, are a small ancient nematocerous family with amphitropical distribution and higher recent diversity in the Southern Hemisphere (Eskov and Lukashevich 2015). Only 18 extinct and extant genera (most of them monotypic) are described in the family, which has been known since the Early Jurassic (Ansorge 1994, Skibińska et al. 2014). In the $19^{\text {th }}$ century tanyderids were described in the family Ptychopteridae, but now the family is usually considered to be close to Psychodidae (Crampton 1926, Alexander 1927, Shcherbakov et al. 1995, Krzemiński et al. 2013); however, some current authors consider it to be closely related to Ptychopteridae (Hennig 1973, Wood and Borkent 1989, Oosterbroek and Courtney 1995) or Blephariceridae (Lambkin et al. 2013; Ptychopteridae were not included in the analysis). Close relationships between Tanyderidae, Blephariceridae and Psychodidae was recently inferred from DNA phylogeny (Bertone et al. 2008, Wiegmann et al. 2011) and possible closeness of Tanyderidae and Psychodidae was inferred from DNA phylogeny of Psychodidae (Curler and Moulton 2012).

The family is important for understanding of the history of the order, but remains insufficiently studied. Male genitalia of some extant genera have been described or drawn with varying degrees of detail; both genera from the Northern Hemisphere: Protoplasa Osten-Sacken, 1860 and Protanyderus Handlirsch, 1909; and most of genera from the Southern Hemisphere: Peringueyomyina Alexander, 1921, Mischoderus Handlirsch, 1909, Araucoderus Alexander, 1929, Eutanyderus Alexander, 1928, Nothoderus Alexander, 1927 and Neoderus Alexander, 1927 (Alexander 1927, 1928, Williams 1933, Colless and McAlpine 1970, Savchenko 1971, 1974, 1978, Borkent and Sinclair 2012, Madriz and Courtney 2016, Madriz 2017, Madriz et al. 2018). Only Peringueyomyina, Araucoderus and Neoderus were described in sufficient detail. Musculature of the terminalia has never been examined in the family.

Among the likely relatives, musculature has been examined in the blepharicerid, Edwardsina gigantea Zwick, 1977 (Zwick 1977), the ptychopterid, Ptychoptera lacustris Meigen, 1830 (Just 1973) and the psychodids, Phlebotomus garnhami Heisch, Guiggsberg \& Teesdale, 1956 (Just 1973), P. papatasi (Scopoli, 1786) (Jobling 1987), Pericoma sp. (Hennig 1936) and Pneumia palustris (Meigen, 1804) (as Pericoma palustris in Just 1973). All examined psychodids are members of more derived subfamilies (Phlebotominae and Psychodinae), whereas musculature for members of basal subfamilies has not yet been described. Additionally, the data of different authors are usually difficult to compare, because a uniform nomenclature of muscles is lacking; moreover, figures of Jobling (1987) are not accompanied by any descriptions. Therefore, as the first step for further comparison, a table with the presumed homology of musculature among families was compiled (Table 1). Recently a similar attempt of homologization was undertaken for other families of Diptera (Spangenberg et al. 2012). 
Study of the musculature is helpful not only for specifying the functions of genital sclerites, but also for revealing the homology of some poorly traced structures (Ovtshinnikova and Yeates 1998, Ovtshinnikova and Galinskaya 2016b, 2017, Galinskaya et al. 2018). Based on morphogenetical regularities formulated by Matsuda (1976) and verified by Ovtshinnikova (1989) and Friedrich and Beutel (2008), characters associated with muscles are confirmed to be more stable than those associated with sclerites and therefore can be used successfully in phylogenetic studies; morphological series of different species are especially productive for such studies.

The purpose of this study was to investigate the skeleton and musculature of the male genitalia of two genera of Tanyderidae from the Southern Hemisphere. The muscles and sclerites of the male abdomen of Nothoderus australiensis (Alexander, 1922) from Tasmania and the muscles of the male abdomen of Araucoderus gloriosus (Alexander, 1920) from Chile are described for the first time.

\section{Material and methods}

This study is based on males of Tanyderidae collected in Nothofagus-dominated forests in Chile and Tasmania by D. Shcherbakov and E. Lukashevich in 2014 and 2015. Specimens studied herein will be deposited in the Zoological Institute RAS, St-Petersburg, Russia. Additional specimens are deposited in the National Museum of Natural History, Santiago, Chile (Araucoderus) and Tasmanian Museum and Art Gallery, Hobart, Australia (Nothoderus).

Scanning electron micrographs of uncoated and coated males were taken with a Tescan Vega microscope using backscattered electron (BSE) and secondary electron (SE) detectors.

The terminology of the male genital sclerites mainly follows Cumming and Wood (2009) with additions on structure of the parameres made by Madriz and Courtney (2016). Description of sclerites of Nothoderus australiensis in this study is modeled on the description of Araucoderus gloriosus from the study of Madriz and Courtney (2016).

The muscular systems of male genitalia were studied by manually dissecting the material (preserved fresh in $70 \%$ alcohol) with microknives in water under a Leica MZ95 stereomicroscope. The pictures were taken using the image capture function of the Leica MZ95 trinocular head and subsequently processed. The male terminalia muscles were classified into several groups: muscles of the epandrial complex, muscles of the hypandrial complex, tergosternal muscles, and pregenital muscles. The muscles were numbered according to the classification previously accepted by Ovtshinnikova with the following modifications $M 21=M 3, M 29=M 7$ and $M 32=M 23$ based on homologization of muscles (Ovtshinnikova 2000).

List of abbreviations: aed - aedeagus; cerc-cercus; ej apod-ejaculatory apodeme; ep - epandrium; goncx - gonocoxite; gonst - gonostylus; hypd - hypandrium; hypp - hypoproct; ISM - abdominal intersegmental sternal muscles; ITM - abdominal intersegmental tergal muscles; lepr - lateral ejaculatory process; $M 1-M 33$ - pregenital 
and genital muscles; $p m d b$ - dorsal bridge of paramere; $p m$ dme - dorsomedial element of paramere; $p m g b l$ - paramere lobe at gonocoxite base; $p m$ lme - lateromedial element of paramere; spm sac - sperm sac; st - sternite; tes - testis; th - thorax; $\mathrm{tg}$ - tergite; TSM - abdominal tergosternal muscles.

\section{Results}

\section{Family Tanyderidae Osten-Sacken, 1880 \\ Subfamily Tanyderinae Osten-Sacken, 1880}

The subfamily includes nine extant and five extinct genera with relatively short gonopods. Musculature of male terminalia is here examined for only two members of the subfamily.

Tanyderidae are characterized by abdominal segments with intersegmental tergal (ITM), intersegmental sternal (ISM) and tergosternal (TSM) muscles and by pregenital muscles $(M 18, M 19)$. Male genital muscles of Tanyderidae are classified into several groups: tergosternal muscles (M5); muscles of the hypandrial complex (3 pairs of ejaculator muscles $M 23, M 30, M 31$; aedeagal muscle $M 1+2 ; 2$ pairs of gonostylar muscles M27, M28); muscles of the epandrial complex (muscles M3, connecting epandrium with hypoproct (=X sternite); muscles $M 7$, connecting hypoproct with cerci).

\section{Araucoderus gloriosus (Alexander, 1920)}

Figures 1A, B, 2-4

Material. Chile, Nothofagus-dominated forest, on riparian vegetation. Alerce Andino

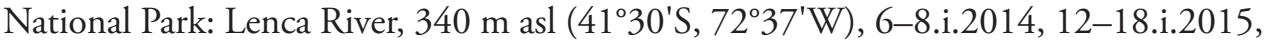
D.E. Shcherbakov, E.D. Lukashevich, 8 males; Puyehue National Park: Anticura River near Anticura Waterfall, $400 \mathrm{~m}$ asl $\left(40^{\circ} 40^{\prime} \mathrm{S}, 72^{\circ} 10^{\prime} \mathrm{W}\right), 14.1 .2014$, E.D. Lukashevich, 1 male; Chanlefu River at Aguas Calientes, $470 \mathrm{~m}$ asl (4044'S, 72 $\left.18^{\prime} \mathrm{W}\right), 16.1 .2014$, D.E. Shcherbakov, 1 male; Huerquehue Natianal Park: near Tiquilco Lake, $780 \mathrm{~m}$ asl, (39 $\left.{ }^{\circ} 10^{\prime} \mathrm{S}, 71^{\circ} 44^{\prime} \mathrm{W}\right), 22 . x i i .2014$, E.D. Lukashevich, 1 male; near La Junta, Rio Palena, $70 \mathrm{~m}$ asl, (4349'S, 72²1'W), 5.i.2015, E.D. Lukashevich, 1 male. The specimens will be deposited in the Zoological Institute RAS, St-Petersburg, Russia.

Exoskeleton. The male terminalia were described in great detail by Madriz and Courtney (2016), so here we describe only the muscles; scanning electron micrographs of genitalia are published for comparison purposes (Figure 1A, B).

Musculature. Thoracic muscles. One pair of tergal muscles, connecting thorax and medial part of tergite I; one pair of sternal muscles, connecting thorax and anterolateral margin of sternite II (Figure 2C).

Abdominal muscles. One pair of long intersegmental tergal muscles ITM1 connecting medial part of tergite I and medial part of tergite II (Figure 2C). Segments I-VII 

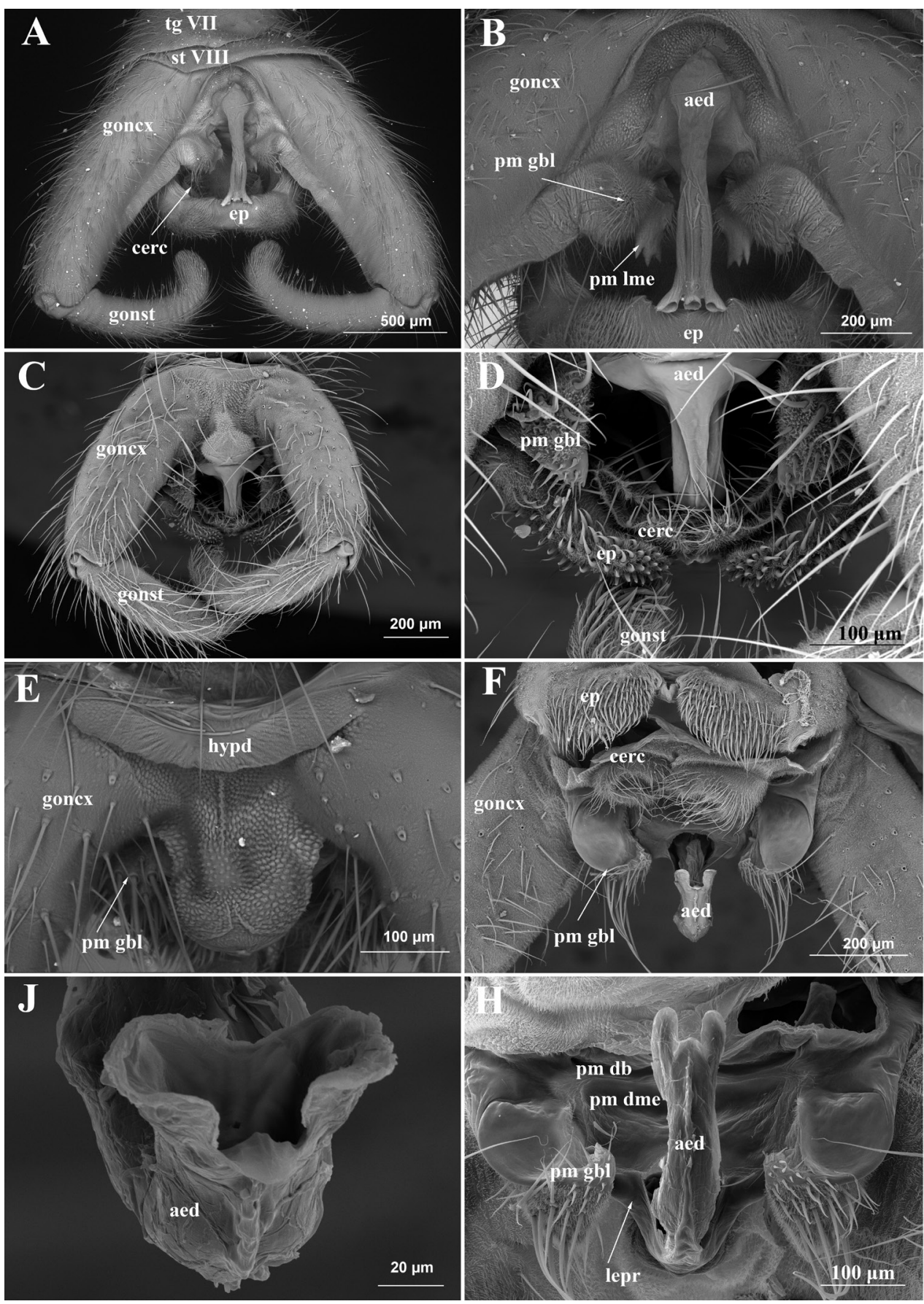

Figure I. SEM images of male genitalia of Tanyderidae. A-B Araucoderus gloriosus (uncoated, BSE; Chile, Alerce Andino), dorsal view C-H Nothoderus australiensis $\mathbf{C}-\mathbf{E}$ dorsal view (uncoated, BSE; Tasmania, Mystery Creek Cave) F-H ventral view (coated, SE; Tasmania, Lake Saint Clair). 

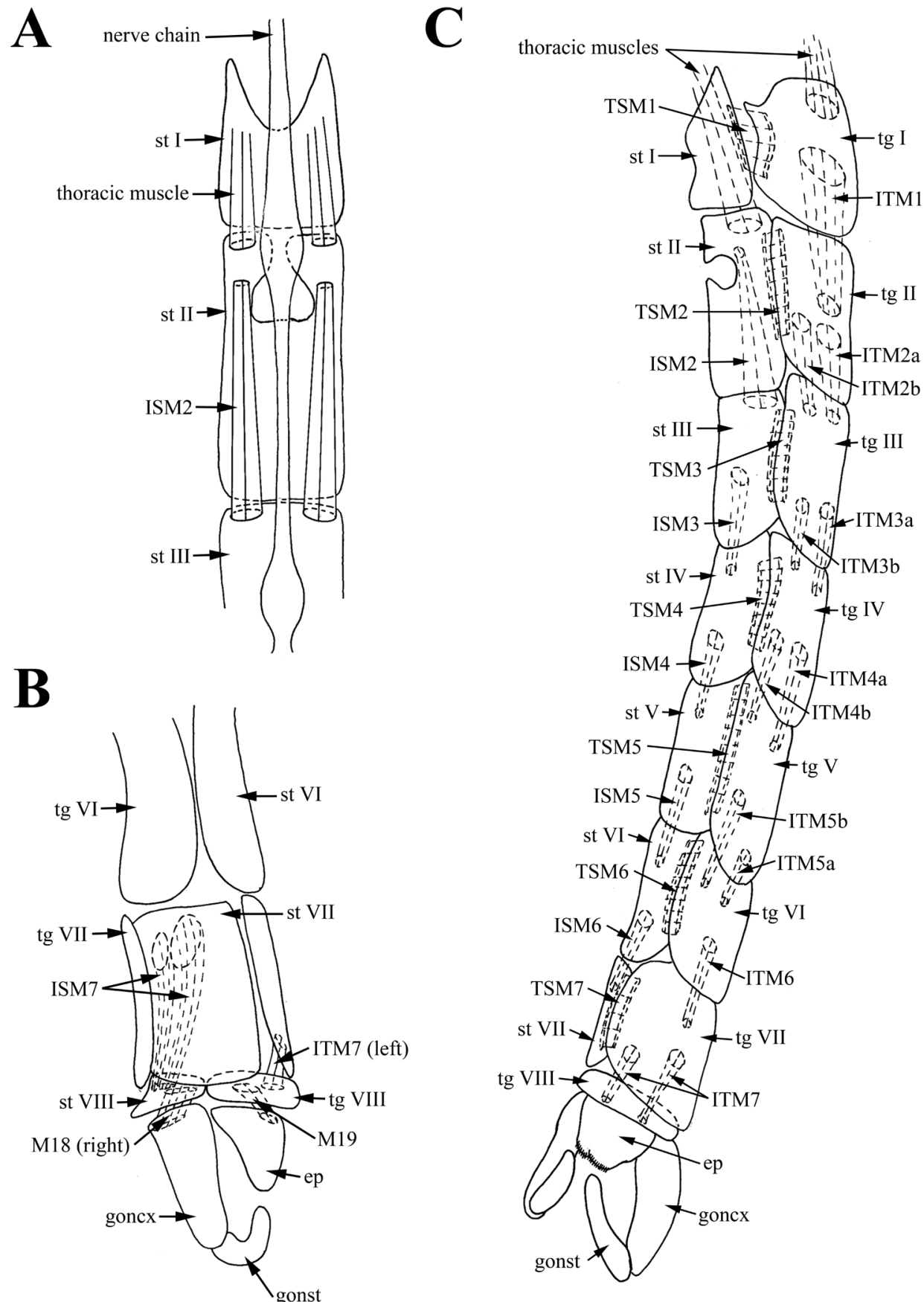

Figure 2. Male of Araucoderus gloriosus. A sternites, inner view B tip of abdomen, right lateral view C abdomen, left lateral view. 
A

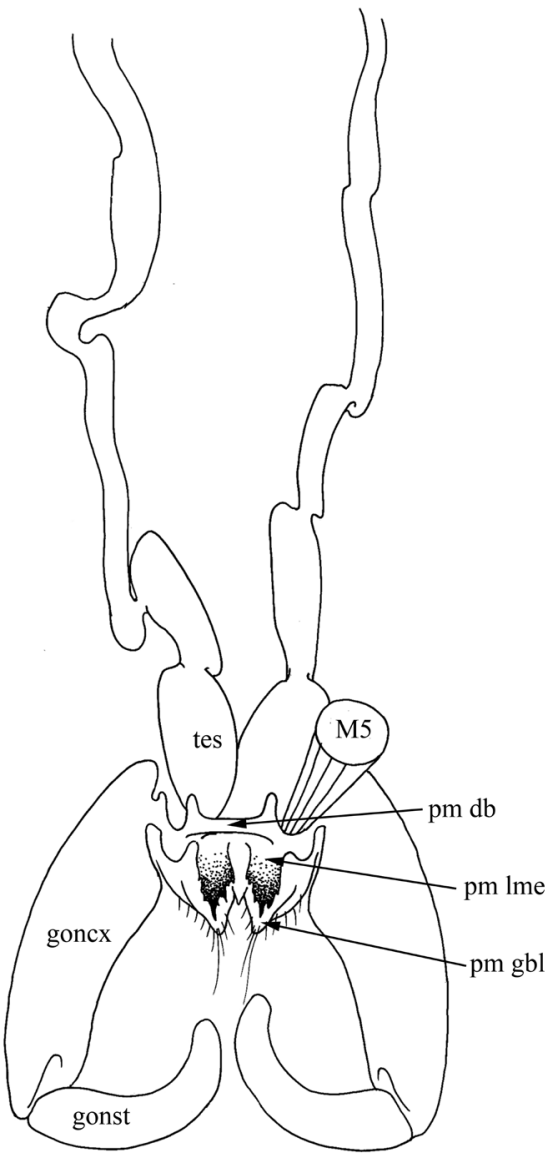

B

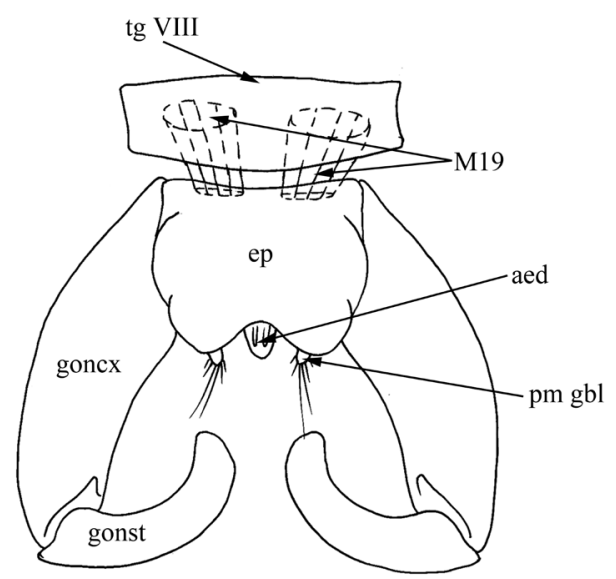

C

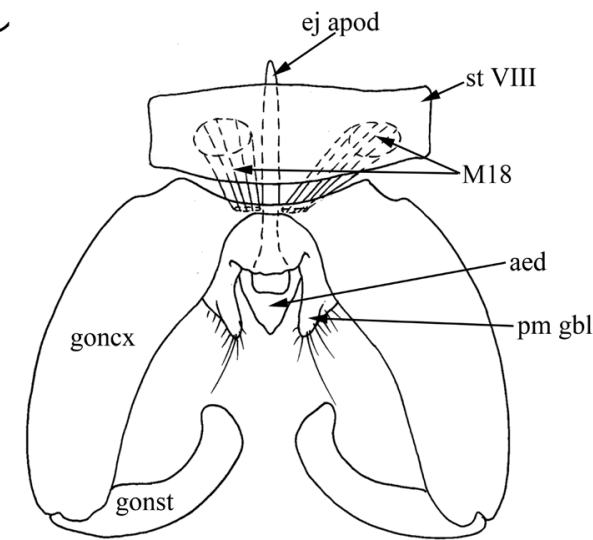

Figure 3. Male of Araucoderus gloriosus. A genitalia, inner view B genitalia, ventral view C genitalia, dorsal view.

with wide, short tergosternal muscles (TSM1-TSM7) (Figure 2C). One pair of long symmetrical intersegmental sternal muscles ISM2 passing from anterior third of sternite II to anterior margin of sternite III. Two pairs of long symmetrical intersegmental tergal muscles $(I T M 2 a, b)$ passing from posterior half of tergite II to anterior margin of tergite III; medial ITM2a slightly thinner and longer, lateral ITM2b slightly stronger but shorter (Figure 2A, C). Intersegmental tergal and sternal muscles on segments III-V with similar attachment sites as intersegmental muscles of segments II-III (Figure 2C). One pair of intersegmental tergal muscles ITMG extending from tergite VI to tergite VII. One pair of intersegmental sternal muscles ISMG extending from sternite VI to sternite VII. Intersegmental muscles ITMG and ISMG thinner than intersegmental muscles of previous segments; posterior sites of attachment of muscles ITMG and ISMG slightly displaced counterclockwise due to terminalia rotation (Figure 2C). One pair of 
A
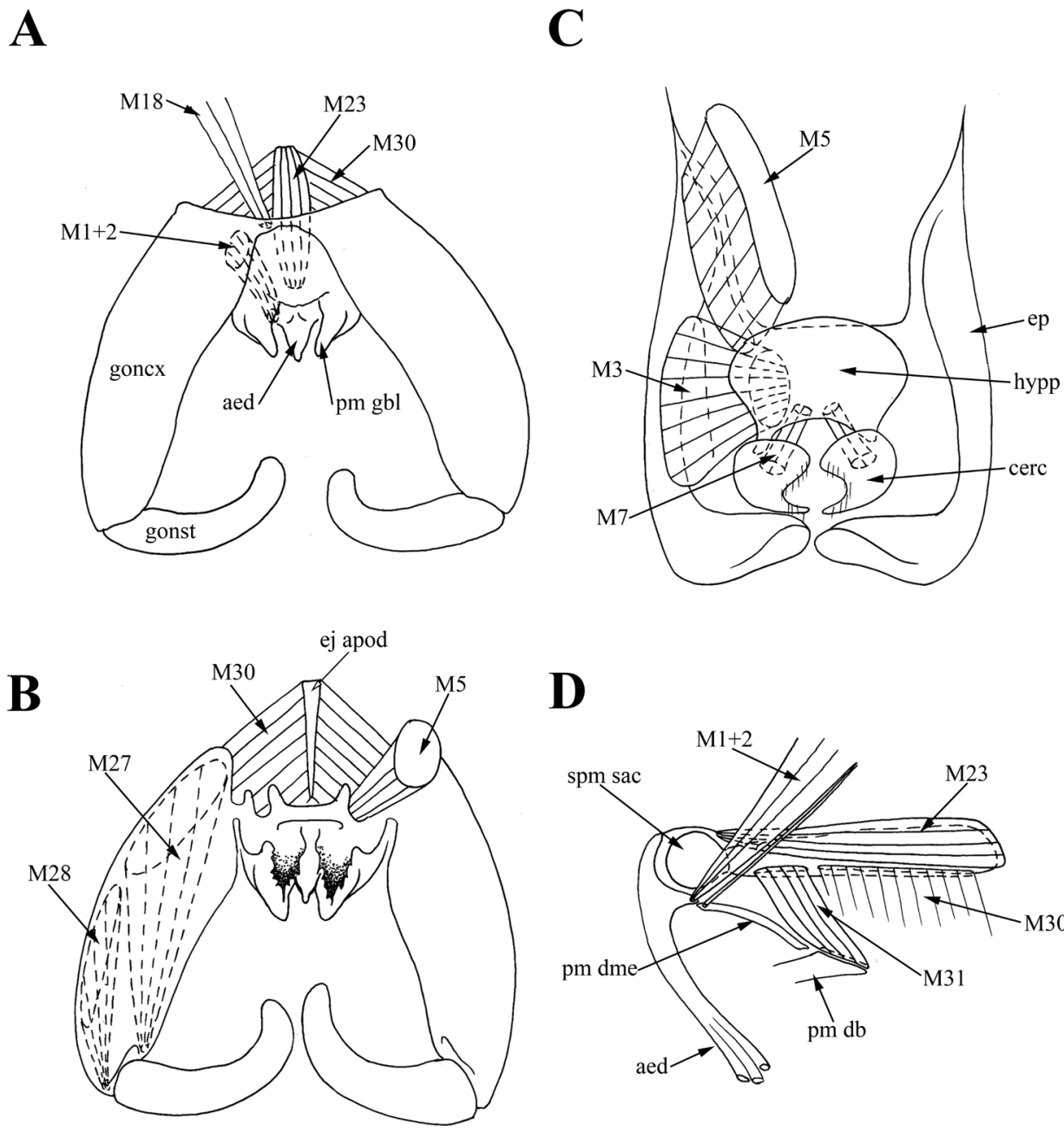

D

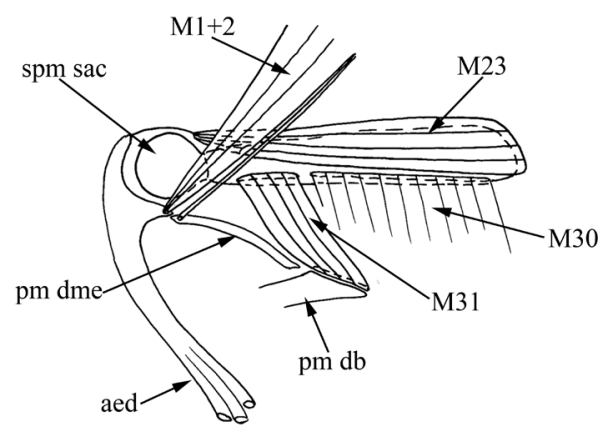

Figure 4. Male of Araucoderus gloriosus. A genitalia, dorsal view B genitalia, inner view C epandrium, inner view $\mathbf{D}$ aedeagal complex, lateral view.

long asymmetrical muscles ISM7 extending from middle of anterior part of sternite VII to left anterior margin of sternite VIII; posterior sites of attachment of muscles ISM7 displaced counterclockwise due to terminalia rotation (Figure 2B). Tergite VIII situated on left side of abdomen. One pair of asymmetrical muscles ITM7 extending from tergite VII to tergite VIII. Right muscle ITM7 long, extending from middle of tergite VII to posterior part of tergite VIII. Left muscle ITM7 short, extending from posterior margin of tergite VII to posterior part of tergite VIII. Posterior sites of attachment of muscles ITM7 displaced counterclockwise due to terminalia rotation (Figure 2B, C).

Pregenital muscles. Paired short asymmetrical muscles M18: right muscle M18 long, connecting middle of right side of sternite VIII to narrow sclerotized stripe or 
hypandrium between gonocoxite bases; left wide short muscle $M 18$ connecting middle of left side of sternite VIII to narrow sclerotized stripe between gonocoxite bases (Figures 2B, 3C). Narrow sclerotized stripe between gonocoxite bases interpreted as hypandrium according to attachment sites of muscles M18. Paired short, wide and slightly asymmetrical muscles $M 19$ extending from center of tergite VIII to anterior margin of epandrium (Figure 3B).

Tergosternal muscles. Paired, wide symmetrical M5 connecting anterolateral parts of epandrium to lateral thickenings of dorsal bridge of paramere in the point of connection of $p m d b$ with gonocoxites (= gonocoxal apodeme) (Figures 3A, 4B, C). Lateral thickenings of dorsal bridge of paramere interpreted as gonocoxites according to attachment sites of muscles M5.

Muscles of the hypandrial complex. Paired long retractors $M 1+2$ extending from anterior edges of gonocoxites to aedeagal condyle, and several muscle filaments of $M 1+2$ extending from anterior edges of gonocoxites to posterior margin of dorsomedial element of paramere $p m$ dme (Figure 4A, D). Paired long M23 extending from posterior edge of ejaculatory apodeme (dorsally) to membrane near aedeagus (Figure 4A, D). Paired wide protractors $M 30$ extending from anterior half of ejaculatory apodeme (laterally) to anterior margin of gonocoxites (Figure 4A, B, D). Paired retractors M31 extending from posterior part of ejaculatory apodeme to medial part of dorsal bridge of paramere $p m d b$ (Figure 4D). Paired long wide M27 extending from anterior part of gonocoxites to ligament near anterior margin of gonostyli (Figure 4B). Paired long wide M28 extending from medial part of gonocoxites to condyle of gonostyli (Figure 4B).

Muscles of the epandrial complex. Paired short wide $M 3$ extending from most of inner epandrium surface to hypoproct (X sternite) (Figure 4C). Paired thin $M 7$ extending from posterolateral parts of hypoproct to cerci (Figure 4C).

\section{Nothoderus australiensis (Alexander, 1922)}

Figures 1C-H, 5, 6

Material. Tasmania, Nothofagus-dominated forest, on riparian vegetation. Lake Saint Clair National Park (426'S, $146^{\circ} 9^{\prime}$ E), 7.xii.2015, D.E. Shcherbakov, 2 males; Mystery Creek Cave ( $43^{\circ} 28^{\prime}$ S, $146^{\circ} 51^{\prime}$ E), 13.xii.2015, D.E. Shcherbakov, E.D. Lukashevich, 4 males. The specimens will be deposited in the Zoological Institute RAS, St-Petersburg, Russia.

Exoskeleton. Abdomen: tergite I about 0.6 times as long as tergite II, sternite I about 0.3 times as long as sternite II (Figure 5). Segments II-VII well developed. Terminalia with $160-180^{\circ}$ rotation of through segments VII-IX, with segment VIII rotated about $80-90^{\circ}$. Segment VIII reduced to one small sclerite situated dorsally (Figure 5B). Gonocoxites and gonostyli pubescent with long setae. Gonocoxites narrowly contiguous at base, divergent from each other at origin, each nearly cylindrical, tapered slightly toward apex (Figures 1C, 5, 6A). Gonostylus cylindrical, about 4/5 length of gonocoxite, slightly tapered at apex, curved medially, with dense macrosetae 
A

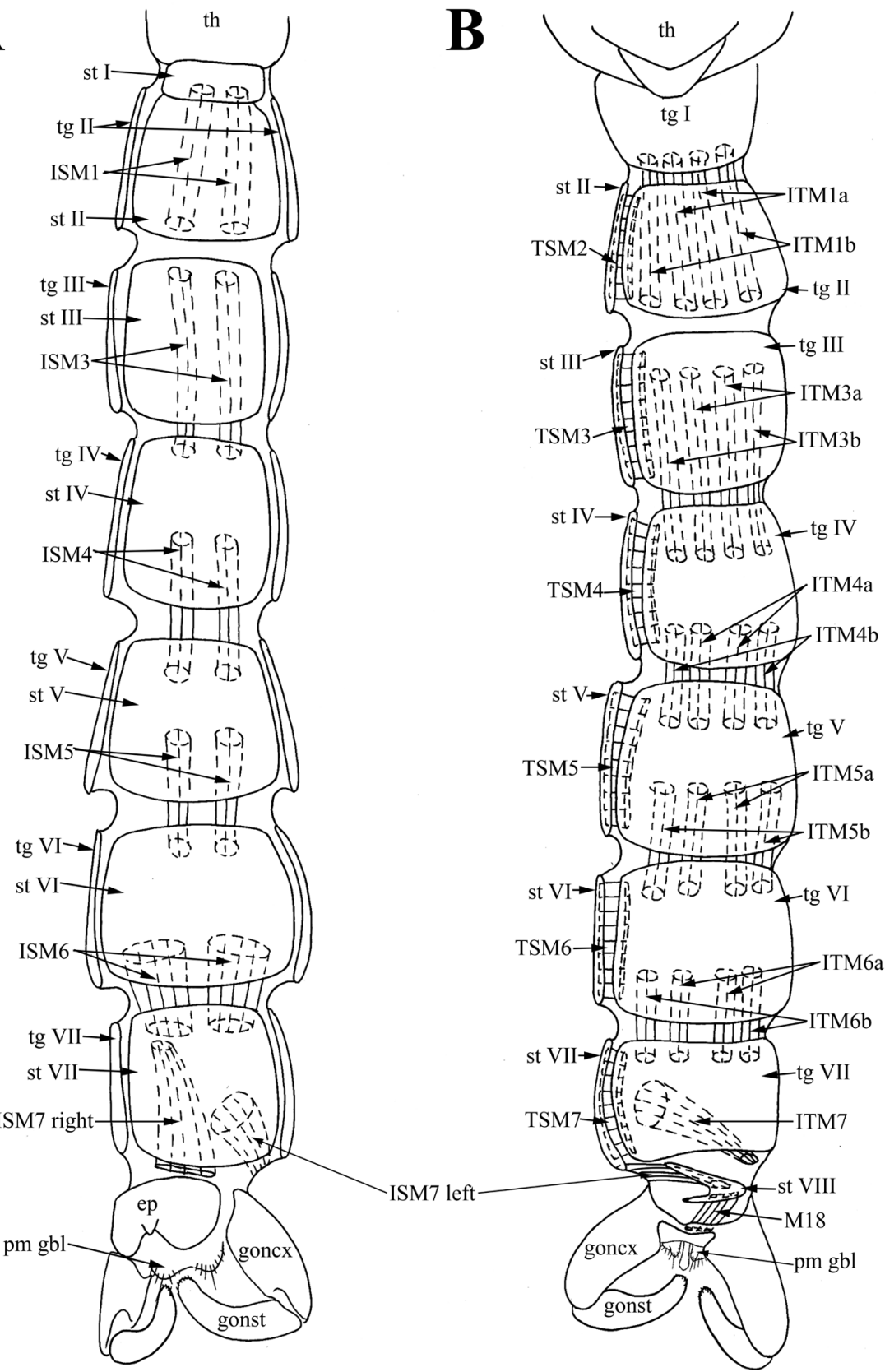

Figure 5. Male of Nothoderus australiensis. A abdomen, ventral view B abdomen, dorsal view.

apically (Figures 1C, D, 5). Apparent hypandrium as narrow sclerotized stripe between gonocoxite bases (Figure 1E), according to muscle attachment sites (see musculature description). Epandrium slightly wider than long, with elongate setae along lateral 
margins and robust closely set macrosetae on two large convex lobes; tiny bare medial lobe between lateral ones; cercus inconspicuous, unmodified, setose, with semicircular rim (Figures 1D, F, 6B). Hypoproct small, situated ventrad of epandrium (Figure 6E). Paramere subdivided into dorsal bridge $(p m d b)$, dorsomedial element $(p m d m e)$ and parameral lobe at gonocoxite base ( $p m g b l$ ) (Figures 1D, F, H, 6B): dorsal bridge archshaped, with one pair of long projections anterolaterally; dorsomedial element "Ishaped", articulated with dorsal bridge basally and with lateral ejaculatory processes of aedeagus apically; parameral lobe at gonocoxite base bare inside and with group of elongated setae among shorter ones outside (Figure 1D, F, H). Ejaculatory apodeme extending anteriorly to segment VII, laterally compressed, clavate at base (Figure 6A, C); sperm sac balloon-like, surrounded by aedeagus posteriorly, attached to ejaculatory apodeme anteriorly; aedeagus relatively short, curved, with single trilobate phallotrema, placed between cerci when at rest (Figure $1 \mathrm{~F}-\mathrm{H})$.

Musculature. Abdominal muscles. Tergosternal muscles TSM1 of segment I not found. Segments II-VII with one pair of wide short tergosternal muscles (TSM2TSM7) (Figure 5B). Two pairs of long symmetrical intersegmental tergal muscles $(I T M 1 a, b)$ extending from posterior part of tergite I to posterior part of tergite II; paired medial ITM1a and paired lateral $I T M 1 b$ with same thickness (Figure 5B). One pair of long intersegmental sternal muscles ISMI connecting posterior part of sternite I to posterior part of sternite II (Figure 5A). Intersegmental tergal and sternal muscles ITM2 and ISM 2 connecting segment II and III not found. Intersegmental symmetrical tergal and sternal muscles ITM3a,b-ITM5a,b and ISM3-ISM5 on segments IIIVI with similar attachment sites as intersegmental muscles of segment I-II (Figure 5). Segments II-VII with wide short tergosternal muscles (TSM2-TSM7) (Figure 5B). Two pairs of intersegmental tergal muscles ITMGa, $b$ extending from posterior part of tergite VI to anterior part of tergite VII. One pair of symmetrical wide intersegmental sternal muscles ISMG passing from posterior part of sternite VI to anterior part of sternite VII. Posterior sites of attachment of muscles ITM $6 a, b$ and ISM 6 slightly displaced clockwise (Figure 5). One pair of long asymmetrical muscles ISM7 right extending from right anterior part of sternite VII to membrane between sternite VII and epandrium. ISM7 left extending from left medial part of sternite VII to sternite VIII (Figure 5). Unpaired muscle ITM7 connecting left medial part of tergite VII to membrane between tergite VII and sternite VIII (Figure 5B).

Pregenital muscles. Short unpaired muscle M18 connecting sternite VIII to narrow sclerotized stripe or hypandrium between gonocoxite bases (Figure 5B). Narrow sclerotized stripe between gonocoxite bases interpreted as hypandrium, according to attachment sites of muscles M18. Muscles M19 not found. Segment VIII decreased to one small dorsal sclerite; tergite VIII completely membranous, sternite VIII reduced to narrow sclerite.

Tergosternal muscles. Paired, wide symmetrical M5 connecting anterolateral parts of epandrium to lateral thickenings of dorsal bridge of paramere in the point of connection of $p m d b$ with gonocoxites (= gonocoxal apodeme) (Figure 6B, C). Lateral thickenings of dorsal bridge of paramere interpreted as gonocoxites according to attachment sites of muscles $M 5$. 
A

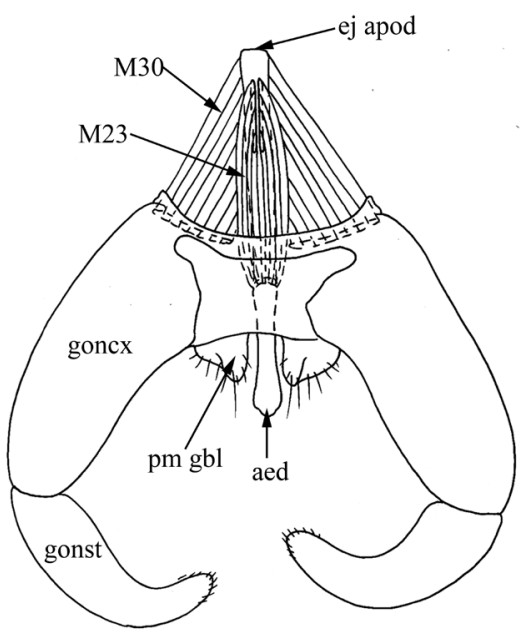

B

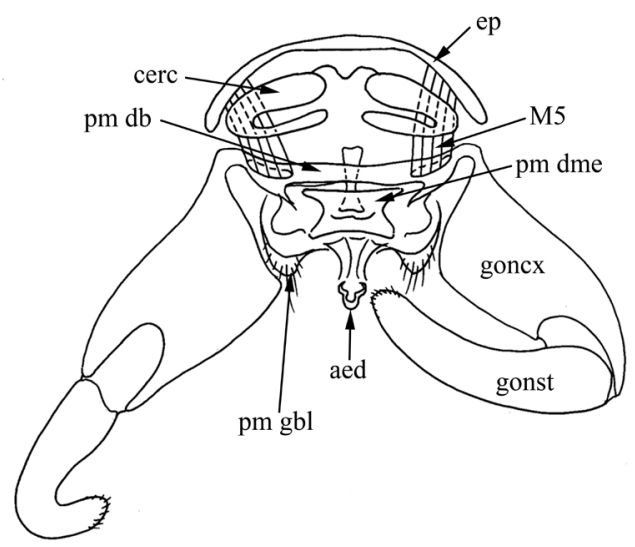

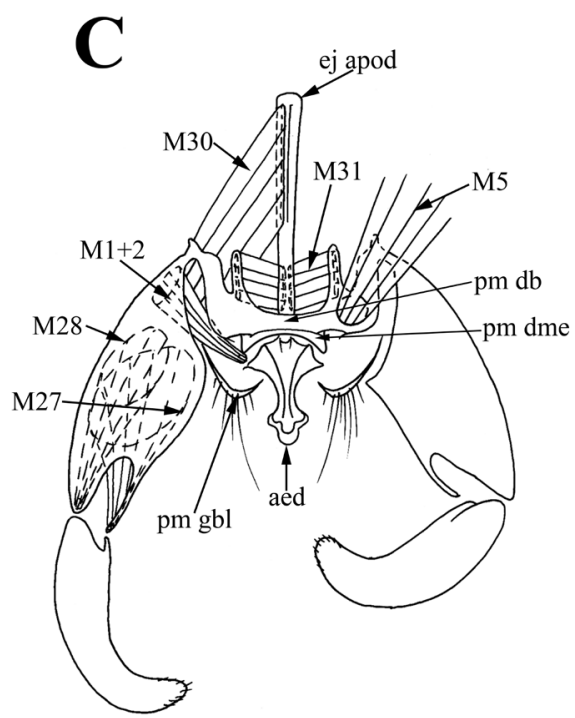

D

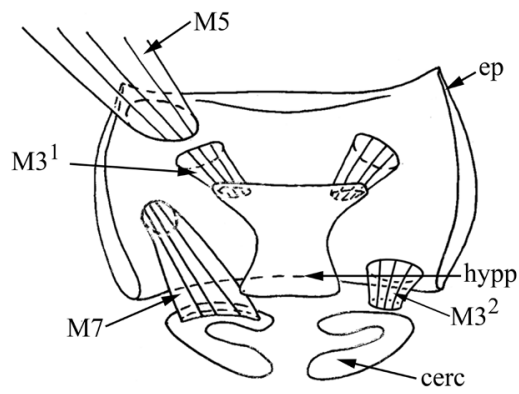

Figure 6. Male of Nothoderus australiensis. A genitalia, dorsal view B genitalia, posterior view C genitalia, inner view $\mathbf{D}$ epandrium, inner view.

Muscles of the hypandrial complex. Paired long retractors $M 1+2$ extending from anterior edges of gonocoxites to aedeagal condyle, and also several muscle filaments of $M 1+2$ extending from anterior edges of gonocoxites to posterior margin of dorsomedial element of paramere $p m d m e$ (Figure 6C). Paired long $M 23$ extending from posterior edge of ejaculatory apodeme (dorsally) to membrane near aedeagus (Figure 6A). Paired wide protractors $M 30$ extending from anterior half of ejaculatory apodeme (laterally) to anterior margin of gonocoxites (= gonocoxal apodeme) (Figure 6A, C). Paired wide retractors $M 31$ extending from posterolateral part of ejaculatory apodeme to medial anterolateral projections of dorsal bridge $p m d b$ (Figure 6C). Paired long wide muscles M27 extending from anterior part of gonocoxites to ligament near anterior margin 
of gonostyli (Figure 6C). Paired long wide $M 28$ extending from anteromedial part of gonocoxites to condyle of gonostyli (Figure 6C).

Muscles of the epandrial complex. Two pairs of $M 3$ muscles; $M 3^{1}$ extending from lateral parts of epandrium to anterolateral parts of hypoproct (X sternite); $M 3^{2}$ extending from posterolateral parts of epandrium to membrane between epandrium and cercus (Figure 6D, E). Paired thin $M 7$ extending from membrane near hypoproct to anterior lobe of cercus (Figure 6E). Hypoproct apparently partly membranous, according to site of attachment of muscles $M 3^{2}$ and $M 7$.

\section{Discussion}

\section{Comparison of Araucoderus and Nothoderus sclerites and musculature}

The sclerites and musculature of Araucoderus and Nothoderus are similar, but differ in several features. The overall pattern of male terminalia of both genera is similar to most of the Southern Hemisphere genera, with simple curved gonostyli, lobe-like setose parameres, and setose cerci inconspicuous under the epandrium. The terminalia of Nothoderus are distinct from genitalia of Araucoderus in shape of epandrium with tiny concave median lobe, absence of sclerotized protruding parameral elements and simple aedeagus. However, these differences in structure of terminalia in Araucoderus and Nothoderus are not associated with differences in musculature. Thus, in Araucoderus parameral elements are more diverse and developed and the structure of trifid and simple aedeagus is different; but the aedeagal muscles $M 1+2$ and ejaculatory muscles $M 23, M 30$ and $M 31$ look very similar in both genera.

We have found different degrees of sclerotization of the hypoproct in Araucoderus and Nothoderus, and correlated differences in muscles of the epandrial complex. The hypoproct is recessed deeply within the genitalia; its location is possibly the reason why the hypoproct was not mentioned by some previous researchers (Krzemiński and Judd 1997). Araucoderus is characterized by the well-developed hypoproct connection to the wide muscles $M 3$, whereas the hypoproct of Nothoderus is partly membranous, according to the site of attachment of muscles $M 3^{2}$ and $M 7$ (both attached not to hypoproct but to a membrane near it). The weakening and division of muscles $M 3$ into two pairs of muscles in Nothoderus is probably associated with this membranization.

One interesting difference associated with rotation was found in the abdominal structure. Nothoderus is characterized by the $180^{\circ}$ rotation of segments VII-IX, of the six specimens examined, four males demonstrated clockwise rotation (two of them only $160^{\circ}$; Figure 5) and two counterclockwise rotation; one of them had its terminalia rotated only $90^{\circ}$. In other families of nematocerous Diptera, this rotation often occurs several days after emergence, so probably it was a young male captured during its first days of activity (for details see Lukashevich 2018).

Araucoderus is also characterized by $180^{\circ}$ rotation of segments VII-IX. However, of the 12 males of Araucoderus examined by us, seven had partially rotated terminalia (about $90^{\circ}$ ) and five males had terminalia with $180^{\circ}$ rotation; eight specimens had 
clockwise rotation and 4 males had counterclockwise rotation (such males are illustrated in Figures 1A, 2). Three males were collected by one of us during one hour on the same beach (Lenca River, Alerce Andino NP, 12.i.2015); one male had terminalia with $90^{\circ}$ clockwise rotation, two others with $90^{\circ}$ and $180^{\circ}$ counterclockwise. Madriz and Courtney (2016, fig. 1) also recorded $90^{\circ}$ and $180^{\circ}$ rotation for Araucoderus gloriosus and figured clockwise rotation on the total view without any mention of reverse cases. The difference of rotation direction is common among nematocerous Diptera; e.g. the rotated genitalia were randomly oriented and similar numbers of clockwise and counterclockwise events were observed in sufficiently large samples within the same species in Culicidae and Psychodidae (Chevone and Richards 1976, Curler et al. 2015, Votypka et al. 2015). We believe that Tanyderidae are not exceptions and both genera have similar rotated terminalia with $180^{\circ}$ (and $90^{\circ}$ as an intermadiate stage), rotation may be either clockwise or counterclockwise in a 1:1 ratio. However, in spite of the similar results, this rotation is carried out in different ways in Araucoderus and Nothoderus.

Araucoderus is characterized by the narrow segment VIII, but not reduction of the separate sternite and tergite VIII. Nothoderus has segment VIII strongly reduced, with tergite VIII totally membranous and sternite VIII as a narrow sclerite. Accordingly, attachment sites and thickness of pregenital muscles are greatly different between the genera: reduction of muscles M19 and unpaired M18 was found in Nothoderus, whereas Araucoderus has paired symmetrical M18 and M19 (see below, Table 1).

The attachment sites of muscles ISM7 and M18 confirm the origin of sternite VIII, and the attachment sites of muscles ITM7 confirm the entire membranization of tergite VIII of Nothoderus (Figure 5). Moreover, attachment sites of muscles M18 (between sternites VIII and IX) confirm the homology of the hypandrium (sternite IX) as the narrowly sclerotized stripe between gonocoxite bases of both Araucoderus and Nothoderus (Figures 1E, 4A, 5B). Localization of these muscle attachment sites is reliable evidence of the hypandrial origin of the sclerites, as it was revealed by us for Diptera Cyclorrhapha (Galinskaya and Ovtshinnikova 2015a, b, Ovtshinnikova and Galinskaya 2016a). Merging of dorsal bridge with gonocoxites is confirming according to attachment sites of muscles MS (M5 connecting anterolateral parts of epandrium to lateral thickenings of dorsal bridge of paramere in the point of connection of $p m d b$ with gonocoxites) (Figure 6B, C).

The reduction and asymmetry of segment VIII is noted for Tanyderidae for the first time. Such reduction of segment VIII contradicts Alexander's opinion of Nothoderus as "the most generalized of the living Tanyderidae" (Alexander 1928). Moreover, the free tip of Sc which was the reason for his conclusion, is not yet known in the fossil record (pers. obs. EDL), so we assume that it is also a derived character.

One more interesting difference was found in the structure of abdominal intersegmental muscles of VII sclerites. These muscles are asymmetrical and the sternal muscles ISM7 are paired in both genera, whereas the tergal muscles ITM7 are paired in Araucoderus but in Nothoderus only one unpaired ITM7 was found (Table 1; Figures 2,5 ). The position of these muscles as well as their symmetry in Ptychopteridae (the family without rotation of male terminalia) indicates that they probably provide the rotational force for inversion of the terminalia in Tanyderidae and Psychodidae. 
Skeleton and musculature of the male abdomen in Tanyderidae...

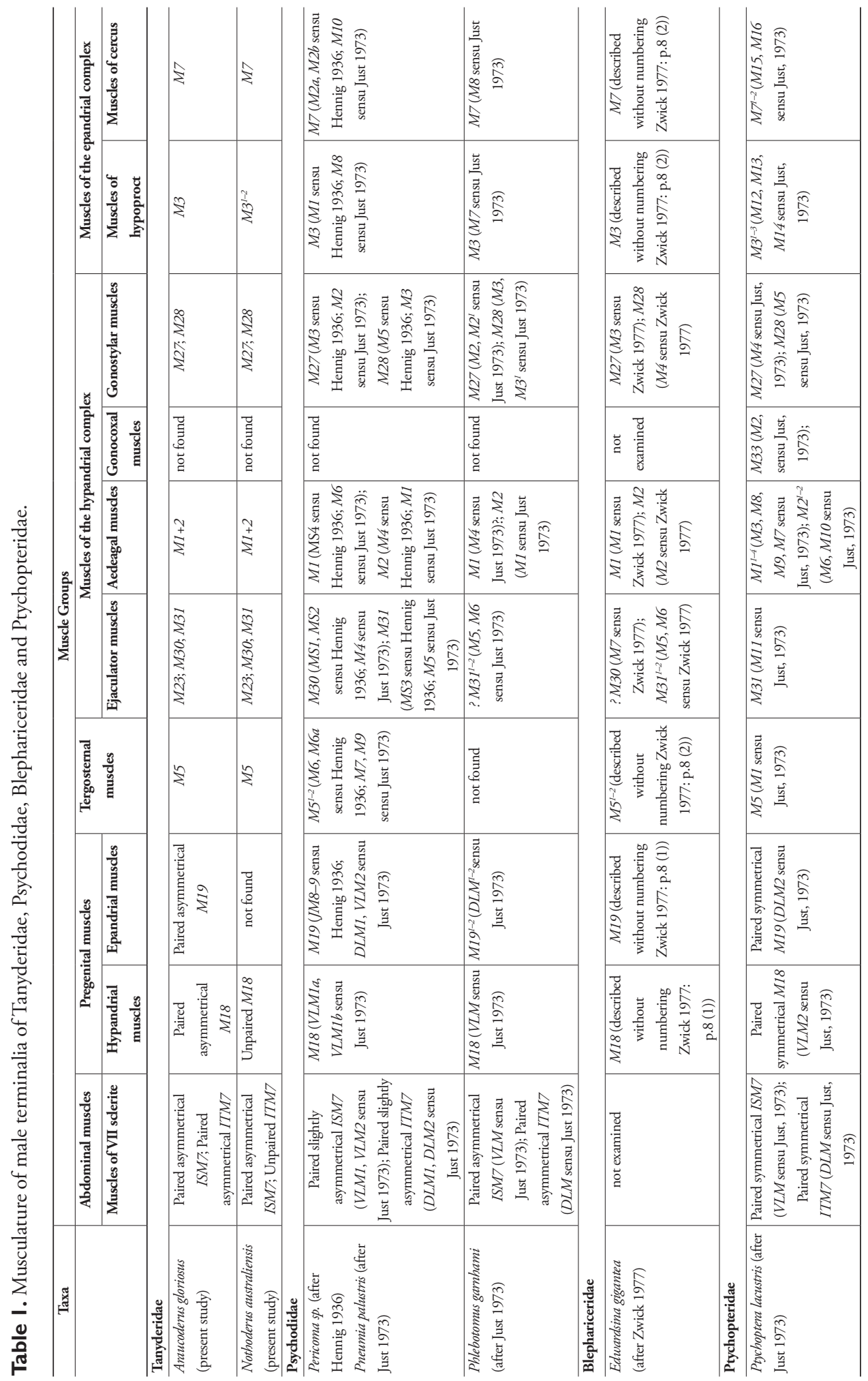




\section{Relationship of Tanyderidae and their supposed relatives: male terminalia evidences}

As it was discussed in the introduction, different authors cluster Tanyderidae with Blephariceridae, Ptychopteridae or Psychodidae. Data on skeleton and musculature of male terminalia in Tanyderidae, Psychodidae, Blephariceridae and Ptychopteridae are compared in Tables 1, 2 and illustrate the noticeable peculiarity of Tanyderidae.

Among these families only Tanyderidae are characterized by ejaculator muscles M23 (in addition to muscles $M 30$ and $M 31$, present in other families). Muscles M23 connect only sclerites or membranes of aedeagal complex consisting of ejaculatory apodeme and aedeagus. Up to now these muscles were recorded in the only one nematocerous family, Trichoceridae, and in Brachycera (as M32 in Ovtshinnikova 1989). Based on our data one can suppose that muscles $M 23$ are present in the groundplan of the Diptera.

It can be assumed that muscles $M 30$ and $M 31$ of Tanyderidae, attached to different parts of the ejaculatory apodeme, have the opposite functions of muscles $M 30$ and $M 31$ of Blephariceridae and Bibionidae and most of Brachycera, muscles M31 of Psychodidae and Ptychopteridae. Muscles M30 of Tanyderidae are, probably, protractors, muscles M31 of Tanyderidae are, probably, retractors as in Trichoceridae (Ovtshinnikova 1989). Protractor muscles in these families are usually wide and fan-shaped, their attachment sites occupy a wide surface of the ejaculatory apodeme, regardless of the origin of the muscles (muscles M30 or M31). At the same time, the other side of the protractor muscles of Tanyderidae is attached to the gonocoxites, therefore the muscles are designated as M30, as well as in the most other families (including Brachycera). Retractors are narrower and often connect to the base of the ejaculatory apodeme. In the Tanyderidae these muscles are connected to parameres, and are designated as $M 31$, in other families these muscles are associated with gonocoxite apodemes or gonocoxites and are designated as M30. Therefore, in this case we assume a complete changing of the functions of these paired antagonist muscles.

Only Tanyderidae are characterized by the merging of aedeagal muscles $M 1$ and M2. Psychodidae, Blephariceridae, and Ptychopteridae are characterized by separate aedeagal muscles: the protractors $M 1$ and retractors of aedeagus $M 2$ and two pairs of aedeagal muscles are part of the dipteran groundplan (one pair $M 1$ and one pair of M2). Tanyderidae are characterized only by retractors $M 1+2$ that should lead to changing in mechanism of aedeagus functioning.

The examined tanyderids are characterized by muscles $M 1+2$ connecting gonocoxites partly to the aedeagus, partly to the dorsomedial element of the parameres pm dme, and by muscles M31 connecting posterior part of ejaculatory apodeme to medial part of dorsal bridge of paramere $p m d b$. Tanyderidae as well as Psychodidae and Blephariceridae are characterized by a sclerotized bridge forming through medial merging of parameres and "connecting the gonocoxites dorsally via the gonocoxal apodemes" (Sinclair 2000). It can be the initial stage of the aedeagal sheath forming: the fused parameres with attached powerful muscles provides protection of the aedeagus and increases the pulling of the aedeagus during copulation, whereas the aedeagus remains well sclerotized and independent. Therefore, the presence of the bridge could be a derived state for Tanyderidae, Psychodidae and Blephariceridae, however, the parameres are fused dorsally in many lineages, e.g. in Trichoceridae, Limoniidae and 
Table 2. Characters of male terminalia of Tanyderidae, Psychodidae, Blephariceridae and Ptychopteridae, discussed in the text (1 - after Just 1973; 2 - after Zwick 1977).

\begin{tabular}{|c|c|c|c|c|c|c|c|c|c|c|}
\hline & \multirow[b]{2}{*}{ Rotation } & \multirow{2}{*}{$\begin{array}{c}\text { Trifid } \\
\text { aedeagus }\end{array}$} & \multirow{2}{*}{$\begin{array}{l}\text { Sperm pump } \\
\text { hypertrophied }\end{array}$} & \multicolumn{2}{|c|}{ Aedeagal muscles } & \multirow{2}{*}{$\begin{array}{l}\text { Tergosternal } \\
\text { muscles M5 }\end{array}$} & \multicolumn{3}{|c|}{ Ejaculator muscles } & \multirow{2}{*}{$\begin{array}{c}\text { Gonocoxal } \\
\text { muscles } \\
\text { M33 }\end{array}$} \\
\hline & & & & M1 & M2 & & M23 & M30 & M31 & \\
\hline \multicolumn{11}{|l|}{ Tanyderidae } \\
\hline $\begin{array}{l}\text { Araucoderus } \\
\text { gloriosus }\end{array}$ & + & + & - & \multicolumn{2}{|c|}{ one pair } & one pair & one pair & one pair & one pair & - \\
\hline $\begin{array}{l}\text { Nothoderus } \\
\text { australiensis }\end{array}$ & + & - & - & \multicolumn{2}{|c|}{ one pair } & one pair & one pair & one pair & one pair & - \\
\hline \multicolumn{11}{|l|}{ Psychodidae } \\
\hline $\begin{array}{l}\text { Pneumia } \\
\text { palustris }^{1}\end{array}$ & + & - & - & one pair & one pair & two pairs & - & one pair & one pair & - \\
\hline $\begin{array}{l}\text { Phlebotomus } \\
\text { garnhami }^{1}\end{array}$ & + & - & - & one pair & one pair & - & - & - & two pairs & - \\
\hline \multicolumn{11}{|c|}{ Blephariceridae } \\
\hline $\begin{array}{l}\text { Edwardsina } \\
\text { gigantea }^{2}\end{array}$ & - & + & - & one pairs & one pair & two pairs & - & one pair & two pairs & - \\
\hline \multicolumn{11}{|c|}{ Ptychopteridae } \\
\hline $\begin{array}{l}\text { Ptychoptera } \\
\text { lacustris }^{1}\end{array}$ & - & - & + & four pairs & two pairs & one pair & - & - & one pair & one pair \\
\hline
\end{tabular}

Axymyiidae (Wood 1991, Sinclair 2000; Paramonov 2004; Sinclair et al. 2013) and it is possible that the dorsal bridge connecting the gonocoxites dorsally via the gonocoxal apodemes is a part of the dipteran groundplan.

Blephariceridae are distinct from Tanyderidae in tergosternal muscles M5 divided into two pairs and the absence of terminalia rotation (Table 2). Within the discussed families only Blephariceridae and Tanyderidae are characterized by a trifid aedeagus with three slender filaments, each with separate openings. There are currently two opinions on the number of aedeagal openings in the dipteran groundplan: three (based on basal number of spermathecae; e.g. Downes 1968, Petersen et al. 2010) or one (based on outgroup comparison, e.g. Wood 1991, Ribeiro 2008). Following the view of Wood (1991) we consider the trifid aedeagus as an apomorphic state, which evolved independently and repeatedly in different families (in Cylindrotomidae and some Brachycera besides Tanyderidae and Blephariceridae). It is obvious that a shift from single to multiple openings has occurred multiple times (Wood 1991) and Tanyderidae is one more example in this sequence (with the single opening in Nothoderus and three phallothremata in Araucoderus). Taking into account a bifid aedeagus (Peringueyomyina and several extinct genera, Madriz 2017, Lukashevich 2018), we can infer that the disparity of the aedeagus structure in tanyderids appears to be the most extreme in the order, which makes it impossible to draw any conclusions on relatives in the absence of an established phylogeny of Tanyderidae.

Ptychopteridae are also distinct from Tanyderidae in the absence of terminalia rotation, and share plesiomorphic characters only, such as tergosternal muscles M5 not divided (Table 2). Ejaculatory-aedeagal complex of Ptychopteridae is very specialized, e.g. the spherical sperm pump is hypertrophied as compared with other dipteran families (including the discussed ones), with only one pair of ejaculator muscles $M 31$ and with six pairs of aedeagal muscles $M 1^{1-3}$ and $M 2^{1-2}$ (Tanyderidae 
are characterized by one pair of merged $M 1+2$ ). Ptychopteridae are characterized by one pair of hypandrial muscles of gonocoxite $M 33$ which is a feature of the groundplan of the Diptera (Paramonov 2004), whereas in Tanyderidae, Psychodidae, and Blephariceridae M33 is absent. We did not find obvious male terminalia synapomorphies grouping Tanyderidae with Ptychopteridae.

Psychodidae is the single family under discussion with male terminalia rotation (for details see in Lukashevich 2018) although genera with unrotated male terminalia are known in Sycoracinae and Horaiellinae (Duckhouse 1972, Curler and Priyadarsanan 2015). In Phlebotomus, the rotation begins with segment VII as in both tanyderids described here. The genus has asymmetrically paired abdominal intersegmental muscles of VII sclerites as in Araucoderus and posterior sites of attachment of muscles ITM7 and ISM7 are slightly moved clockwise (Just 1973), similar to Nothoderus, but unpaired abdominal or pregenital muscles were not found in Psychodidae. We believe that Tanyderidae is closely related to Psychodidae, but the musculature of male terminalia offers rather little confirmation of this relatedness: we did not find any important similarities in the musculature of Psychodidae and Tanyderidae. The absence of M33 in both families is not such an important similarity, although M33 was found in Ptychopteridae, Trichoceridae, Pediciidae, Tipulidae and in some Bibionomorpha and Brachycera and is a considered part of the dipteran groundplan (Ovtshinnikova 1989, Paramonov 2004). However, M33 is also absent in Limoniidae and some Bibionidae (Ovtshinnikova 1989, Paramonov 2004), so its loss seems to have occurred several times independently.

It is worth noting that Psychodidae are extremely diverse and the scarce data on their musculature confirms this diversity: e.g., Psychodinae are characterized by tergosternal muscles $M 5$ divided into two pairs, whereas Phlebotominae are characterized by absence of muscles M5 (Just 1973, Jobling 1987, figure 111). At the same time, muscles M5 are usually very stable within different families of Diptera (Ovtshinnikova 1989, 1993, 2000); e.g., Limoniidae has M5 but M5 is absent in Tipulidae and this character is considered an autapomorphy of the latter family by Paramonov (2004). Due to such diversity within Psychodidae, it is impossible to make serious conclusions based on only two examined derived genera, Pneumia and Phlebotomus, while data on more basal subfamilies are absent. Bruchomyiinae has been referred to as the sister group to the remaining Psychodidae by some authors (Quate and Alexander 2000) and earlier this subfamily was even included in Tanyderidae (Alexander 1927), whereas other authors hypothesized a more basal position for Sycoracinae and Horaiellinae (Curler and Moulton 2012), but the musculature of these subfamilies has not been studied.

\section{Conclusions}

The Tanyderidae are characterized by very specialized sclerites and muscles of male terminalia; these structures provide no evidence of relationship with previously studied members of Psychodidae, Blephariceridae and Ptychopteridae. Within these three families, only Psychodidae have obligatory $180^{\circ}$ male terminalia rotation and only 
Blephariceridae have a trifid aedeagus. Although our initial hypothesis was the similarity of Tanyderidae and Psychodidae and we looked for evidence using the analysis of musculature characters that had not previously been investigated; the musculature of male terminalia offers little confirmation of this relatedness. The absence of evidence is probably connected with the absence of data on musculature of the primitive psychodid subfamilies Bruchomyiinae, Sycoracinae and Horaiellinae.

\section{Acknowledgements}

E.D. Lukashevich is grateful to Dmitry Shcherbakov (Borissiak Paleontological Institute RAS, Moscow) for the opportunity to collect Tanyderidae in Chile and Tasmania. E.D. Lukashevich is also grateful to Cathy Byrne and Simon Grove (both Tasmanian Museum and Art Gallery, Hobart) for their hospitality and invaluable help in facilitating field work of the Russian team in Tasmania and to Mario Elgueta (National Museum of Natural History, Santiago) for facilitating fieldwork in Chile. We also thank Roman Rakitov (Borissiak Paleontological Institute of Russian Academy of Sciences, Moscow) for helping in taking scanning electron images and for other assistance. We are deeply indebted to Rolf G. Beutel (Institut für Spezielle Zoologie und Evolutionsbiologie, Jena) and Bradley J. Sinclair (Canadian National Collection of Insects and Canadian Food Inspection Agency, Ottawa) for insightful comments on the manuscript and linguistic advice.

The work of O.G. Ovtshinnikova was supported by the Zoological Institute of Russian Academy of Sciences (State Research Program AAAA-A17-1 17030310205-9) and the Russian Foundation for Basic Research (project no. 18-04-00354-a). The work of T.V. Galinskaya was supported by the Russian Science Foundation (project no. 14-14-00208). The research of E.D. Lukashevich was partly supported by grants from the Russian Foundation for Basic Research, projects no. 13-04-01839 and 16-04-01498.

\section{References}

Alexander CP (1920) A new genus and species of net-winged midge (Blepharoceridae) and an undescribed species of Tanyderidae (Diptera). Arkiv för Zoologi 13(7): 1-7.

Alexander CP (1921) A new genus and species of Tanyderid (Peringueyomina barnardi) in the South African Museum (Diptera). Annals of the South African Museum 18: 231-234.

Alexander CP (1922) Undescribed crane-flies (Tanyderidae and Tipulidae) in the South Australian museum. Records of the South Australian Museum 2: 223-270.

Alexander CP (1927) Diptera fam. Tanyderidae. Genera Insectorum 189: 1-13.

Alexander CP (1928) Tanyderidae of Australia (Diptera). Proceedings of the Linnean Society of New South Wales 53: 367-374.

Alexander CP (1929) Diptera of Patagonia and South Chile. Part I. Crane-flies (Tipulidae, Trichoceridae, Tanyderidae). British Museum (Natural History), London, 240 pp. 
Ansorge J (1994) Tanyderidae and Psychodidae (Insecta: Diptera) from the Lower Jurassic of northeastern Germany. Paläontologisches Zeitschrift 68 (1-2): 199-209. https://doi. org/10.1007/BF02989440

Bertone MA, Courtney GW, Wiegmann BM (2008) Phylogenetics and temporal diversification of the earliest true flies (Insecta: Diptera) based on multiple nuclear genes. Systematic Entomology 33: 668-687. https://doi.org/10.1111/j.1365-3113.2008.00437.x

Borkent A, Sinclair BJ (2012) The male genital tract of Axymyiidae and Tanyderidae (Diptera). The Canadian Entomologist 144: 266-272. https://doi.org/10.4039/tce.2012.26

Chevone BI, Richards AG (1976) Ultrastructure of the atypic muscles associated with terminalial inversion in male Aedes aegypti (L). The Biological Bulletin 151: 283-296. https://doi. org/10.2307/1540661

Colless DH, McAlpine DK (1970) Chapter 34. Diptera. In: Waterhouse DF (Ed.) Insects of Australia. Melbourne University Press, Melbourne, 656-740.

Crampton GC (1926) A phylogenetic study of the thoracic sclerites of the Psychodoid Diptera, with remarks on the interrelationships of the Nematocera. Entomological News 37(3): 33-39, 65-70.

Cumming JM, Wood DM (2009) Adult morphology and terminology. In: Brown BV, Borkent A, Cumming JM, Wood DM, Woodley NE, Zumbado M (Eds) Manual of Central American Diptera. Volume 1. Research Press, Ottawa, 9-50.

Curler GR, Moulton JK (2012) Phylogeny of psychodid subfamilies (Diptera: Psychodidae) inferred from DNA sequences with a review of morphological evidence for relationships. Systematic Entomology 37: 603-616. https://doi.org/10.1111/j.1365-3113.2012.00634.x

Curler GR, Moulton JK, Madriz RI (2015) Redescription of Aposycorax chilensis (Tonnoir) (Diptera, Psychodinae, Sycoracinae) with the first identification of a blood meal host for the species. Zootaxa 4048(1): 114-126. https://doi.org/10.11646/zootaxa.4048.1.7

Curler GR, Priyadarsanan DR (2015) Descriptions of Psychodidae (Diptera) from the Western Ghats of India. Acta Entomologica Musei Nationalis Pragae 55(2): 473-483.

Downes JA (1968) Notes on the organs and processes of sperm-transfer in the lower Diptera. The Canadian Entomologist 100 (6): 608-617. https://doi.org/10.4039/Ent100608-6

Duckhouse DA (1972) Psychodidae (Diptera, Nematocera) of South Chile, subfamilies Sycoracinae and Trichomyiinae. Transactions of the Royal Entomological Society of London 124(3): 231-268. https://doi.org/10.1111/j.1365-2311.1972.tb00365.x

Eskov KY, Lukashevich ED (2015) On the history of ranges of two relict nematoceran families, Ptychopteridae and Tanyderidae (Insecta: Diptera): a biogeographical puzzle. Russian Entomological Journal 24: 257-270.

Friedrich F, Beutel RG (2008) The thorax of Zorotypus (Hexapoda, Zoraptera) and a new nomenclature for the musculature of Neoptera. Arthropod Structure \& Development 37: 29-54. https://doi.org/10.1016/j.asd.2007.04.003

Galinskaya TV, Gafurova D, Ovtshinnikova OG (2018) X-ray microtomography (microCT) of male genitalia of Nothybus kuznetsovorum (Nothybidae) and Cothornobata sp. (Micropezidae). ZooKeys 744: 139-147. https://doi.org/10.3897/zookeys.744.22347

Galinskaya TV, Ovtshinnikova OG (2015a) Musculature of the male genitalia in the tribe Ulidiini (Diptera, Ulidiidae). Entomological Review 95(1): 31-37. https://doi.org/10.1134/ S0013873815010042 
Galinskaya TV, Ovtshinnikova OG (2015b) Musculature of the male genitalia in Rivellia (Diptera: Platystomatidae). ZooKeys 545: 149-158. https://doi.org/10.3897/zookeys.545.6702 Handlirsch A (1909) Zur Phylogenie und Flügelmorphologie der Ptychopteriden (Dipteren). Annalen des k.k. Naturhistorischen Hofmuseum in Wien 23: 263-272.

Heisch RB, Guiggsberg CAW, Teesdale C (1956) Studies in leishmaniasis in Eastern Africa. II. The sandflies of the Kuiti Kala-Azar area in Kenya, with descriptions of six new species. Transactions of the Royal Society of Tropical Medicine and Hygiene 50: 209-226. https:// doi.org/10.1016/0035-9203(56)90025-6

Hennig W (1936) Der männliche Kopulationsapparates der Dipteren. III, Psychodidae und Asilidae. Zoologischer Anzeiger 114(7-8): 177-186.

Hennig W (1973) Ordnung Diptera (Zweiflügler). Handbuch der Zoologie 4(2, 2/31): 1-337. Jobling B (1987) Anatomical drawings of biting flies, British Museum (Natural History). British Museum (Natural History) and the Wellcome Trust, London, 119 pp.

Just JP (1973) Die Anatomie der Postabdomina von Phlebotomus garnhami Heisch, Guiggsberg and Teesdale, Pericoma palustris Meigen und Liriope lacustris Meigen (Diptera, Nematocera). Zoologishe Jahrbücher, Abteilung für Anatomie und Ontogenie der Tiere 91(3): 305-388. Krzemiński W, Azar D, Skibińska K (2013) Nannotanyderus ansorgei sp. n., the first member of the family Tanyderidae fromthe Lebanese amber (Lower Cretaceous). In: Azar D, Engel M, Jarzembowski E, Krogmann L, Santiago-Blay J (Eds) Insect Evolution in an Amberiferous and Stone Alphabet: Proceedings of the $6^{\text {th }}$ International Congress on Fossil Insects, Arthropods and Amber. Brill, Leiden-Boston, 131-143.

Krzemiński W, Judd DD (1997) Family Tanyderidae. In: Papp L, Darvas B (Eds) Contributions to a Manual of Palaearctic Diptera (with special reference to flies of economic importance). Volume 2. Nematocera and Lower Brachycera. Science Herald, Budapest, 281-289.

Lambkin CL, Sinclair BJ, Pape T, Courtney GW, Skevington JH, Meier R, Yeates DK, Blagoderov V, Wiegmann BM (2013) The phylogenetic relationships among infraorders and superfamilies of Diptera based on morphological evidence. Systematic Entomology 38: 164 -179. https://doi.org/10.1111/j.1365-3113.2012.00652.x

Lukashevich ED (2018) Male terminalia and their rotation in Tanyderidae (Diptera, Nematocera) since the Mesozoic. Historical Biology. https://doi.org/10.108/08912963.2018.15 00568 [published online]

Madriz RI (2017) 15. Tanyderidae. In: Kirk-Spriggs AH, Sinclair BJ (Eds) Manual of Afrotropical Diptera. Volume 2. Nematocerous Diptera and lower Brachycera. Suricate 5. South African National Biodiversity Institute, Pretoria, 479-485.

Madriz RI, Astorga A, Lindsay T, Courtney GW (2018) A new species of Neoderus Alexander, 1927 (Diptera: Tanyderidae) from southern Chile, with a first description of a male and key to extant genera of the family. Aquatic Insects. https://doi.org/10.1080/01650424.20 18.1456665

Madriz RI, Courtney GW (2016) The Neotropical tanyderid Araucoderus gloriosus (Alexander) (Diptera, Tanyderidae), with description of the egg, larva and pupa, redescription of adults, and notes on natural history. Zootaxa 4158(3): 325-351. https://doi.org/10.11646/ zootaxa.4158.3.2

Matsuda R (1976) Morphology and Evolution of the Insect Abdomen. Pergamon Press Ltd., Headington Hill, 534 pp. 
Meigen JW (1804) Klassifikazion und Beschreibung der europäischen zweiflügeligen Insekten (Diptera Linn.). Erster Band. Reichard, Braunschweig, 314 pp.

Meigen JW (1830) Systematische Beschreibung der bekannten europäischen zweiflügeligen Insekten. Sechster Theil. Schulz, Hamm, 401 pp.

Oosterbroek P, Courtney G (1995) Phylogeny of the nematocerous families of Diptera (Insecta). Zoological Journal of the Linnean Society 115: 267-311. https://doi.org/10.1006/zjls.1995.0080

Osten-Sacken CR (1860) New genera and species of North American Tipulidae with short palpi, with attempt at a new classification of the tribe. Proceedings of the Academy of Natural Sciences of Philadelphia 1859: 197-256.

Osten-Sacken CR (1880) Die Tanyderina, eine merkwürdige Gruppe der Tipuliden. Verhandlungen der kaiserlich-kongiglichen zoologish-botanischen Gesellschaft in Wien 29: 517-522.

Ovtshinnikova OG (1989) Muscles of the male genitalia of Brachycera-Orthorrhapha (Diptera). Trudy Zoologicheskogo Instituta Akademii Nauk SSSR 190: 1-166. [in Russian]

Ovtshinnikova OG (1993) Homologies of the male genital sclerites of Diptera Brachycera based on the study of the muscles. Entomological Review 72(4): 737-746.

Ovtshinnikova OG (2000) Muscles of the Male Genitalia of Syrphidae (Diptera). NA Kholodkovsky Memorial Lectures: a Report to the $52^{\text {nd }}$ Annual Meeting, April 1, 1999. St. Petersburg, 70 pp. [in Russian]

Ovtshinnikova OG, Galinskaya TV (2016b) Musculature of the male genitalia of a member of the genus Teleopsis Rondani, 1875 (Diopsidae, Diptera). Oriental Insects 50(2): 61-68. https://doi.org/10.1080/00305316.2016.1227733

Ovtshinnikova OG, Galinskaya TV (2016a) Musculature of the abdomen and male genitalia of a member of Celyphidae (Diptera, Cyclorrhapha). Oriental Insects 50(4): 178-186. https://doi.org/10.1080/00305316.2016.1227733

Ovtshinnikova OG, Galinskaya TV (2017) The male abdominal, genital and pregenital sclerites and musculature in Neria commutata (Czerny, 1930) (Diptera, Micropezidae). Entomological Review 97(3): 282-287. https://doi.org/10.1134/S0013873817030022

Ovtshinnikova OG, Yeates DK (1998) Male genital musculature of Therevidae and Scenopinidae (Diptera: Asiloidea): structure, homology and phylogenetic implications. Australian Journal of Entomology 37(1): 27-33. https://doi.org/10.1111/j.1440-6055.1998.tb01539.x

Paramonov NM (2004) Taxonomic position of the families Tipulidae and Limoniidae in Nematocera (Diptera) with account of characters of the male genital skeleton and muscles. Entomological Review 84(1): 15-30.

Petersen MJ, Bertone MA, Wiegmann BM, Courtney GW (2010) Phylogenetic synthesis of morphological and molecular data reveals new insights into the higher-level classification of Tipuloidea (Diptera). Systematic Entomology 35: 526-545. https://doi.org/10.1111/ j.1365-3113.2010.00524.x

Quate LW, Alexander B (2000) Synopsis of the New World Nemapalpus (Diptera, Psychodiddae, Bruchomyiinae) with description of four new species. Annals of the Entomological Society of America 93: 185-193. https://doi.org/10.1603/0013-8746(2000)093[0185:SOTNW $\mathrm{N}] 2.0 . \mathrm{CO} ; 2$

Ribeiro GC (2008) Phylogeny of the Limnophilinae (Limoniidae) and early evolution of the Tipulomorpha (Diptera). Invertebrate Systematics 22: 627-694. https://doi.org/10.1071/IS08017 
Savchenko EN (1971) On the discovery of tanyderids (Diptera, Tanyderidae) in Mongolia. Entomologicheskoye obozreniye (Entomological Review) 50(1): 167-170.

Savchenko EN (1974) The second species of the primitive crane-flies (Diptera, Tanyderidae) from the Soviet Middle Asia. Zoologicheskiy zhurnal (Zoological Journal) 53(12): 1892-1894.

Savchenko EN (1978) Tanyderid-flies (Diptera, Tanyderidae) of the USSR fauna. Report AS UkrSSR 1: 74-77.

Scopoli JA (1786) Deliciae florae et faunae Insubricae seu novae, aut minus cognitae species plantarum et animalium quas in Insubria Austriaca tam spontaneas, quam exoticas vidit, descripsit, et aeri incidi curavit. Pars II. S.Salvatoris, Ticini, $115 \mathrm{pp}$.

Shcherbakov DE, Lukashevich ED, Blagoderov VA (1995) Triassic Diptera and initial radiation of the order. International Journal of Dipterological Research 6: 75-115.

Sinclair BJ (2000) 1.2. Morphology and terminology of Diptera male terminalia. Manual of Palearctic Diptera 53-74.

Sinclair BJ, Cumming JM, Brooks SE (2013) Male terminalia of Diptera (Insecta): a review of evolutionary trends, homology and phylogenetic implications. Insect Systematict \& Evolutions 44: 373-415. https://doi.org/10.1163/1876312X-04401001

Skibińska K, Krzemiński W, Coram RA (2014) Discovery of the most ancient member of family Tanyderidae (Diptera) from the Lower Jurassic (Sinemurian) of England. Zootaxa 3857: 125-130. https://doi.org/10.11646/zootaxa.3857.1.6

Spangenberg R, Hünefeld F, Schneeberg K, Beutel RG (2012) The male postabdomen and reproductive system of Bibio marci Linnaeus, 1758 (Hexapoda: Diptera: Bibionidae). Journal of Zoological Systematics and Evolutionary Research 50(4): 264-288. doi: 10.1111/j.1439-0469.2012.00669.x

Votypka J, Pavlasova M, Volfova V, Volf P (2015) Rotation of male genitalia in various species of phlebotomine sandfly. Medical and Veterinary Entomology 29: 355-360. https://doi. org/10.1111/mve. 12132

Wiegmann BM, Trautwein MD, Winkler IS, Barr NB, Kim J-W, Lambkin C, Bertone MA, Cassel BK, Bayless KM, Heimberg AM, Wheeler BM, Peterson KJ, Pape T, Sinclair BJ, Skevington JH, Blagoderov VV, Caravas J, Kutty SN, Schmidt-Ott U, Kampmeier GE, Thompson FC, Grimaldi DA, Beckenbach AT, Courtney GW, Friedrich M, Meier R, Yeates DK (2011) Episodic radiation in the fly tree of life. Proceedings of the Natural Academy of Sciences 108: 5690-5695. https://doi.org/10.1073/pnas.1012675108

Williams IW (1933) The external morphology of the primitive tanyderid dipteron Protoplasa fitchii O.S., with notes on the other Tanyderidae. Journal of the New York Entomological Society 41: 1-35.

Wood DM (1991) Homology and phylogenetic implications of male genitalia in Diptera. The ground plan. In: Weisman L, Orsragh I, Pont AC (Eds) Proceedings of the Second International Congress of Dipterology. The Hague, 255-284.

Wood DM, Borkent A (1989) Phylogeny and classification of the Nematocera. In: McAlpine JF (Ed.) Manual of Nearctic Diptera Volume 3. Research Branch, Agriculture Canada, Ottawa, 1333-1370.

Zwick P (1977) Australian Blephariceridae (Diptera). Australian Journal of Zoology Supplement Series 46: 1-121. https://doi.org/10.1071/AJZS046 